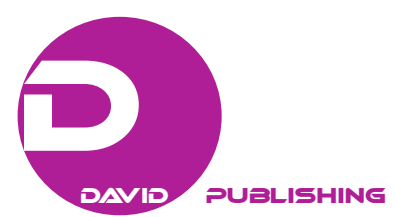

\title{
Thought Confidence: Consumer Emotions and the Confidence Premise Hypothesis
}

\author{
Hsuan-Yi Chou \\ National Sun Yat-sen University, Kaohsiung City, Taiwan
}

\begin{abstract}
Thought confidence, a subjective perception of metacognition, and the accompanying self-validated effects that occur when thought confidence is induced after exposure to persuasive messages have recently received increasing attention from scholars. This construct/mechanism has received little exploration in the past, while there remain important research gaps. One question is whether thought confidence can play different roles when induced at different times; another is whether more variables can be identified which effectively induce confidence in existing or subsequent thoughts. The current paper examines a possible antecedent of thought confidence (i.e., consumer emotions) and explores the effects of thought confidence induced in consumers before they are exposed to advertisements. The author posited the confidence premise hypothesis, which holds that higher consumer confidence is a prerequisite for the significantly positive effects of argument strength in advertisements. Eighty-one undergraduates participated in a 2 (emotions: good moods vs. neutral moods) $\times 2$ (argument strength: strong arguments vs. weak arguments) between-subjects experiment. Experimental results indicate that consumers' emotions positively affect their confidence in thoughts generated later. There is an anticipated pattern of interaction between emotions and argument strength in affecting advertising effectiveness, which supports the confidence premise hypothesis. The implications of these and other findings are discussed.
\end{abstract}

Keywords: thought confidence, metacognition, self-validated hypothesis, consumer emotions, confidence premise hypothesis, argument strength

\section{Introduction}

The role and effects of consumer metacognition in the persuasion process have recently received increasing attention. Some researchers have started to explore a new construct, thought confidence in elaboration-likelihood model (ELM) studies. They have posited the self-validation hypothesis to describe the effects of thought confidence (Briñol, Petty, \& Tormala, 2004; Petty, Briñol, \& Tormala, 2002). The self-validation hypothesis holds that when a person has higher confidence in his/her thoughts, the impact of these thoughts on affecting attitudinal responses is greater. Therefore, when the arguments in an ad are weak and consumers' thoughts are mostly negative, increased thought confidence would further worsen attitudes. When the arguments are strong and thoughts are mostly positive, the higher confidence their thoughts have, the more favorable consumers' attitudes become. However, if argument strength is moderate and thoughts are

Hsuan-Yi Chou, associate professor, Institute of Marketing Communication, National Sun Yat-sen University, Kaohsiung City, Taiwan.

Correspondence concerning this article should be addressed to Hsuan-Yi Chou, 70, Lien-hai Rd., Kaohsiung City 804, Taiwan. 
mixed, the effects of thought confidence disappear.

In most of the previous studies, thought confidence had been either manipulated or measured after study participants were exposed to persuasive messages and thought-listing procedures (e.g., Briñol, Petty, \& Barden, 2007; Clark \& Thiem, 2015; Evans \& Clark, 2012; Petty et al., 2002; Tormala, Briñol, \& Petty, 2006). The effects of thought confidence that were induced prior to or during ad exposure remain underinvestigated. As any variable can play multiple roles in the persuasion process (Petty \& Wegener, 1999), it is likely that thought confidence may take on multiple roles in different situations. This is an interesting issue worthy of exploration. Therefore, the first purpose of this paper is to explore the role of thought confidence when induced prior to ad exposure. The author believed that in this context, thought confidence may influence attitudes in a way different from that of the self-validation hypothesis.

Briñol et al. (2007) indicated that consumer emotions (happy or sad moods) can positively affect thought confidence and then trigger self-validated effects; however, in their experiments, consumers' emotions were manipulated or evoked only following ad exposure and thought-listing tasks. Tormala, Briñol, and Petty (2007) suggested that confidence-enhancing factors affect thought confidence only when they are induced after the message. The impact of experienced emotions on information processing, attitudinal formation, and persuasion is important and has received increasing attention in consumer psychology (Forgas, 2001). The relationship between consumer emotions and persuasion is complicated due to the multiple effects of emotions via multiple processes (Petty \& Briñol, 2015; Petty, Schumann, Richman, \& Strathman, 1993). Therefore, the second purpose of this paper is to re-test the effects of consumer emotions to demonstrate empirically whether or not emotions induced prior to ad exposure have a positive effect on thought confidence.

In order to fulfill both research purposes, the author has chosen to use the same confidence-enhancing factor (i.e., emotions) that has been used in previous studies. This helps to ensure that any differing observed effects of thought confidence are caused by the different times at which thought confidence is induced, rather than by different confidence-enhancing factors. In the following sections, the author first reviews the literature and develops formal hypotheses. Then, the author described and reported on an experiment conducted to test the hypotheses. Finally, the author concluded this article with discussion of main implications and some avenues for future research.

\section{Literature Review and Hypothesis}

As a cognitive construct, thought confidence reflects a subjective sense of validity regarding one's thoughts (Briñol et al., 2004). The self-validation hypothesis indicates that the higher the confidence one has in one's thoughts, the greater the impact of those thoughts on attitudes will be (Petty et al., 2002). Petty et al. (2002) and Briñol et al. (2004) demonstrated that self-validation effects were quite robust even across methodological variations, such as using different types of experimental products, manipulating the valence of thoughts in different ways, and changing the manipulation/measurement methods of thought confidence. However, self-validation effects were shown as more apparent for individuals who engaged in a higher degree of elaboration compared to those engaged in a lower degree of elaboration (Briñol et al., 2007; Petty et al., 2002); this is because high-elaboration contexts cause people to generate more thoughts, thereby providing more materials to be validated or invalidated.

Several antecedents of thought confidence have been identified, including source credibility, source attractiveness, powerful position, body postures, emotions, stereotype activation, perceived entitativity of group 
message sources, and consumers' dispositional optimism (Briñol et al., 2004; 2007; Petty, Briñol, Valle, Rucker, \& Becerra, 2007; Briñol, Petty, \& Wagner, 2009; Chou, Lien, \& Liang, 2011; Clark \& Thiem, 2015; Clark, Wegener, Briñol, \& Petty, 2009; Tormala et al., 2006; 2007). Few previous studies have explored the antecedents of thought confidence in advertising or persuasive message contexts. Briñol et al. (2004) and Tormala et al. (2006) showed that source credibility can determine people's thought confidence; the greater the credibility, the higher the confidence people have in their thoughts about a persuasive message. Additionally, Petty et al. (2007) noted that a powerful position positively affected people's general sense of confidence. Evans and Clark (2012) examined the interaction of source characteristics (expertise and attractiveness) and people's self-monitoring on affecting thought confidence and persuasion. Outside of advertising contexts, Briñol et al. (2007) found that emotion was also a determinant; happy consumers, compared to sad ones, have more thought confidence. Tormala, Petty, and Briñol (2002) suggested that ease of retrieval can affect thought confidence. When the number of thoughts that one is asked to provide is smaller, people will find it easier to generate sufficient thoughts and have more confidence in the quality of the thoughts. Clark et al. (2009) found that stereotype activation increased people's confidence in previous stereotype-consistent thoughts. Horcajo, See, Briñol, and Petty (2008) claimed that mortality salience increased the confidence with which people held their thoughts.

Whether previous studies directly manipulated thought confidence (Petty et al., 2002) or indirectly manipulated it via confidence-enhancing factors (Briñol et al., 2004; 2007; Clark \& Thiem, 2015; Evans \& Clark, 2012), most experimental procedures induced thought confidence following the thought-listing task; then, participants assessed thought confidence and attitudes whereby self-validation effects occurred. Limited research has explored the effects of thought confidence induced at different times. However, there have been some practical difficulties in using previous experimental procedures (i.e., inducing confidence after ad messages) in the real world. In non-laboratory situations, how do companies provide confidence-enhancing/inducing information to advertisement viewers after they have already processed the ad's message and generated their thoughts? Moreover, if the time interval between generating thoughts and receiving confidence-enhancing information is long, viewers may have forgotten their product-related thoughts, which is detrimental to the occurrence of self-validated effects. Therefore, if confidence can be induced prior to or during ad exposure and still have beneficial effects, it will be easier for practitioners to use thought confidence in advertising practices.

Thought confidence in this paper will be induced prior to ad exposure (i.e., at a different time than those which occurred in previous studies); therefore, it is reasonable to surmise that its role in persuasion processes will be different. This paper posits two hypotheses. One is the positive effects of emotions on thought confidence when emotions are evoked prior to ad exposure. The other is what the author terms as the confidence premise hypothesis. According to mood-as-information theory (Schwarz, Bless, \& Bohner, 1991), people's emotions/moods have a global informational value. Negative affective states are theorized to inform individuals that something is wrong with their current environment, thereby reducing their confidence in their behavior following such states. In contrast, positive mood states are believed to signal that the current situation is safe and people's thoughts are fine, thereby enhancing their thought confidence. Studies on appraisal theory (Demir, Desmet, \& Hekkert, 2009) have shown that the experience of some emotions, such as happiness, will cause people to feel a sense of certainty; these emotions increase people's sense that they understand what is happening in the current situation and that they are able to predict what will happen next. Therefore, when 
people are experiencing positive emotions, they also have higher confidence in subsequent thoughts generated soon thereafter.

H1: Consumers' emotions positively affect confidence in their future thoughts.

Argument strength/quality means that the ad contains strong or weak arguments in favor of the products (Briñol et al., 2004). People usually generate mostly favorable thoughts with respect to the strong arguments and mostly unfavorable thoughts in regards to the weak arguments. Argument strength has a positive impact on consumer ad responses, especially in the high product-involvement condition (Petty, Cacioppo, \& Schumann, 1983).

This paper posits that when higher thought confidence is induced prior to ad exposure, consumers may feel more persuaded by the arguments in the following ads. The author referred to this effect as the confidence premise hypothesis, which holds that if consumers have a relatively low level of confidence in thoughts that will be generated soon, thus doubting their ability to generate valid thoughts, they will lack the motivation to process the arguments in ads, whether the arguments are strong or weak. Therefore, the effect of argument strength is weakened. The manipulation of argument strength has anticipated effects only when consumers have relatively high thought confidence. The confidence premise hypothesis also draws theoretical support from the Fishbein model (1967). Bennett and Harrell (1975) suggested that consumers' confidence in their brand beliefs should influence how those beliefs affect their related behavioral intentions. When consumers' beliefs are weighted by their confidence in those beliefs, the Fishbein model (1967) provides a superior prediction of behavioral intentions; that is, the model performs better for consumers with confidence than for consumers without confidence. Therefore, in this study, if product arguments and corresponding product-related thoughts generated by consumers are considered brand beliefs, then the predictive power of argument strength in the ads would be intensified, when consumers have higher confidence in their thoughts/beliefs. However, for consumers who are not confident, the effect of argument strength would be weakened.

H2: The positive effects of argument strength are more salient, when consumers have higher confidence in their thoughts generated later (i.e., the confidence premise hypothesis).

\section{Research Methods}

Undergraduates were selected to be the research samples in this study, as they have been in previous studies (Briñol et al., 2004; Evans \& Clark, 2012; Tormala et al., 2006); this makes the findings from the present study comparable to those of previous studies. Eighty-one undergraduates (43.2\% male and 56.8\% female), ranging in age from 17 to $24(M=21.1)$, participated in a 2 (emotions: good moods vs. neutral moods) $\times 2$ (argument strength: strong arguments vs. weak arguments) between-subjects experiment. They were randomly assigned to one of the four experimental groups.

The participants were asked to view a print ad for a new digital camera with a fictitious brand name. The ad contained five product arguments selected through a pretest that were either all strong (e.g., 1-cm near picturing function and portrayal tracing technology) or all weak (e.g., direct-print function and metal body). Because thought confidence has been shown to play a more important role in the high-elaboration condition (Petty et al., 2002), the author of this study attempted to increase the extent of participants' elaboration by increasing their product involvement using the methods in works of Petty et al. (1983) and Petty, Harkins, and Williams (1980). 
After an introduction session, the participants in the good-mood condition were asked to imagine that they had won a free travel package to Greece in a game show; further, it was suggested they really love this tour and are planning to purchase a new digital camera for recording the upcoming happy overseas travel. The participants in the neutral-mood condition were asked to imagine that they will travel with several unfamiliar friends and are asked by friends to bring a camera.

Immediately after the ad, referred to Wright's thought listing procedure (1980), participants were asked to spend one to three minutes listing all thoughts that they had when viewing the ad and then evaluating each thought listed as positively, negatively, or neutrally valenced. After the thought-listing task, participants assessed the extent to which they had confidence in their thoughts with a four-item (confident, certain, valid, and convincing), seven-point scale (not at all to extremely; Briñol et al., 2004; Petty et al., 2002). Next, they assessed the items of ad attitudes (good/bad, favorable/unfavorable, pleasant/unpleasant, and positive/negative), brand attitudes (good/bad, favorable/unfavorable, like/dislike, and valuable/worthless), and their purchase intentions of the advertised product at the next purchase occasion (likely/unlikely, possible/impossible, and probable/improbable; Pascal, Sprott, \& Muehling, 2002); further, they assessed manipulation checks of argument strength (unpersuasive/persuasive and weak reasons/strong reasons; Petty et al., 1983), the extent of elaboration (low thinking/high thinking and low attention paid/high attention paid; Petty et al., 2002), and emotions (bad mood/good mood, sad/happy, irritable/pleased, and depressed/cheerful; Swinyard, 1993). Upon completion of the questionnaire, the participants were thoroughly debriefed, thanked, and dismissed. The Cronbach alpha reliabilities for all variable scales were higher than 0.83 .

Two trained judges who were blind to the hypotheses and the experimental treatment conditions classified each thought into three types independently: product-related, ad execution-related, or miscellaneous. Inter-judge reliability (Perreault \& Leigh, 1989) for thought categorization was 0.93, with disagreements resolved by discussion. The scores of net product-related thoughts were calculated by subtracting the number of negative product-related thoughts from the number of positive product-related thoughts (Muehling \& Sprott, 2004).

\section{Research Results}

For manipulation checks, the participants who received the imaginary scenario of good moods had higher scores $(M=5.49)$ on the measure of moods than those receiving the imaginary scenario of neutral moods $(M=$ 4.08, $p<0.05$ ). Additionally, the participants rated argument strength as stronger when responding to strong arguments $(M=4.85)$ than to weak ones $(M=2.89, p<0.05)$. The extent of elaboration was successfully set as a high level $(M=4.86>4, p<0.05)$.

After running a series of analyses of variance, the results (shown in Table 1) revealed that the participants with good moods had higher confidence in their thoughts than those with neutral moods ( $M=5.69$ vs. 5.15, $p<$ 0.05), thereby supporting H1. Argument strength had significantly positive effects on net product-related thoughts $(M=1.90$ vs. $-0.90, p<0.05)$, ad attitudes $(M=4.61$ vs. $3.91, p<0.05)$, brand attitudes $(M=4.87$ vs. 4.04, $p<0.05$ ), and purchase intentions $(M=4.21$ vs. $2.93, p<0.05)$. Simple main effects suggested that there was an interaction between emotions and argument strength on ad attitudes, brand attitudes, and purchase intentions. When the participants had good moods, argument strength significantly positively affected ad attitudes ( $M=4.91$ vs. 3.86, $p<0.05)$, brand attitudes ( $M=5.10$ vs. 3.94, $p<0.05)$, and purchase intentions ( $M$ $=4.59$ vs. $2.75, p<0.05)$. However, when the participants were in neutral moods, the significantly attitudinal 
effects of argument strength disappeared (all $p>0.05$ ), though strong arguments still had more positive impact. Thus, the effect of argument strength was more evident when consumers were in good moods (i.e., they had higher thought confidence), thereby supporting the confidence premise hypothesis, hence, H2 was supported. The author also tested whether or not another interaction pattern existed. For strong arguments, the manipulation of emotions did not affect any indices of advertising effects (all $p>0.05$ ), and neither did the emotion manipulation in the weak arguments condition (all $p>0.05$ ). Therefore, the findings did not support the self-validation hypothesis.

Table 1

Means and ANOVA Results

\begin{tabular}{|c|c|c|c|c|c|c|c|c|}
\hline & \multicolumn{2}{|c|}{ Good moods } & \multicolumn{2}{|c|}{ Neutral moods } & \multicolumn{4}{|c|}{ ANOVA $F$ values ( $p$ values) } \\
\hline & $\begin{array}{l}\text { Strong } \\
\text { AS }\end{array}$ & $\begin{array}{l}\text { Weak } \\
\text { AS }\end{array}$ & $\begin{array}{l}\text { Strong } \\
\text { AS }\end{array}$ & $\begin{array}{l}\text { Weak } \\
\text { AS }\end{array}$ & Emotions & AS & $\begin{array}{l}\text { Emotions } \\
\text { AS }\end{array}$ & $x$ \\
\hline Thought confidence & 5.94 & 5.44 & 5.17 & 5.14 & $\begin{array}{l}7.733 \\
(0.007)^{* *}\end{array}$ & $\begin{array}{l}1.900 \\
(0.172)\end{array}$ & $\begin{array}{l}1.538 \\
(0.219)\end{array}$ & \\
\hline N. product-related thoughts & 2.36 & -0.88 & 1.44 & -0.92 & $\begin{array}{l}0.864 \\
(0.356)\end{array}$ & $\begin{array}{l}29.176 \\
(0.000)^{* *}\end{array}$ & $\begin{array}{l}0.710 \\
(0.402)\end{array}$ & \\
\hline Ad attitudes & 4.91 & 3.86 & 4.32 & 3.96 & $\begin{array}{l}0.964 \\
(0.329)\end{array}$ & $\begin{array}{l}8.003 \\
(0.006)^{* *}\end{array}$ & $\begin{array}{l}1.920 \\
(0.170)\end{array}$ & \\
\hline Brand attitudes & 5.10 & 3.94 & 4.64 & 4.15 & $\begin{array}{l}0.270 \\
0(.605)\end{array}$ & $\begin{array}{l}11.718 \\
(0.001)^{* *}\end{array}$ & $\begin{array}{l}1.957 \\
(0.166)\end{array}$ & \\
\hline Purchase intentions & 4.59 & 2.75 & 3.83 & 3.11 & $\begin{array}{l}0.339 \\
(0.562)\end{array}$ & $\begin{array}{l}13.919 \\
(0.000)^{* *}\end{array}$ & $\begin{array}{l}2.621 \\
(0.110)\end{array}$ & \\
\hline
\end{tabular}

Notes. N. = net; $\mathrm{AS}=$ argument strength; $* p<0.05$; and $* * p<0.01$.

\section{General Discussion}

\section{Conclusions}

This study found that consumers' emotions positively affect their confidence in thoughts generated later. There is an anticipated pattern of interaction between emotions and argument strength on affecting advertising effectiveness, which supports the confidence premise hypothesis. Specifically, higher consumer confidence is a prerequisite for the significantly positive effects of argument strength in advertisements.

\section{Implications}

This study contributed to thought confidence literature by demonstrating that emotions manipulated prior to ad exposure still have positive effects on thought confidence. The difference between this approach and that of manipulating emotions after ad exposure (Briñol et al., 2007) is that of consumers' confidence being placed on later-generated thoughts or existing thoughts. Additionally, this study found a different role that thought confidence can play. Thought confidence, as induced through the induction of good moods prior to ad exposure, is a prerequisite for the significant effects of the product arguments in an ad. The confidence premise effect of thought confidence is different from the self-validation effect discussed in previous studies (e.g., Briñol et al., 2004; 2007; Clark \& Evans, 2014; Petty et al., 2002); this suggests that future scholars should further examine the different roles of thought confidence in various contexts. In a high-elaboration setting, this study demonstrated that consumers' emotions can affect advertising effectiveness through the differently influential mechanism of thought confidence, which contributes to the increased understanding of the relationship between affect and cognition. 
The novel experimental procedure used to induce thought confidence in this study provides practitioners with an easier way to improve consumers' attitudes and purchase intentions. Generally, when selling high-involvement products, companies provide strong arguments to communicate the advantages of their products. According to the findings of the current study, it will benefit companies to manipulate consumers to be in good moods prior to ad exposure or to search for ideal situations or times to place ads (i.e., after consumers have read funny comic books or have seen variety shows). When consumers therefore have higher thought confidence, strong ad arguments would more likely yield the anticipated effects and generate improved positive consumer responses. Companies could also try to elicit higher consumer thought confidence prior to ad exposure with other ways and strategies, in addition to emotional manipulation and/or mood capitalization.

\section{Future Research Suggestions}

Future research should re-test the confidence premise hypothesis with different products and samples in order to establish robustness and generalization. Additionally, other variables that could elicit higher thought confidence prior to ad exposure are worthy of further exploration. Furthermore, consumers' thoughts that come to mind after reading the ads might be product-related or ad-execution related. As this study does not change the design of ad-execution elements in different experimental conditions, consumers' net ad-execution related thoughts are similar in each condition and are not discussed. Future research could also explore the possible effect of confidence on ad-execution thoughts when ad-execution elements (i.e., spokespersons and background music) are manipulated.

\section{References}

Bennett, P. D., \& Harrell, G. D. (1975). The role of confidence in understanding and predicting buyers' attitudes and purchase intentions. Journal of Consumer Research, 2(2), 110-118.

Briñol, P., Petty, R. E., \& Barden, J. (2007). Happiness versus sadness as a determinant of thought confidence in persuasion: A self-validation analysis. Journal of Personality and Social Psychology, 93(5), 711-727.

Briñol, P., Petty, R. E., \& Tormala, Z. L. (2004). Self-validation of cognitive responses to advertisements. Journal of Consumer Research, 30(4), 559-573.

Briñol, P., Petty, R. E., \& Wagner, B. (2009). Body posture effects on self-evaluation: A self-validation approach. European Journal of Social Psychology, 39(6), 1053-1064.

Chou, H. Y., Lien, N. H., \& Liang, K. Y. (2011). The antecedents and belief-polarized effects of thought confidence. The Journal of Psychology, 145(5), 481-506.

Clark, J. K., \& Evans, A. T. (2014). Source credibility and persuasion: The role of message position in self-validation. Personality and Social Psychology Bulletin. $\quad$ Retrieved from http://psp.sagepub.com/content/early/2014/05/12/0146167214534733.abstract

Clark, J. K., \& Thiem, K. C. (2015). Group communicators, perceived entitativity, and persuasion: A self-validation analysis. Journal of Experimental Social Psychology, 61, 5-11.

Clark, J. K., Wegener, D. T., Briñol, P., \& Petty, R. E. (2009). Discovering that the shoe fits: The self-validating role of stereotypes. Psychological Science, 20(7), 846-852.

Demir, E., Desmet, P. M. A., \& Hekkert, P. (2009). Appraisal patterns of emotions in human-product interaction. International Journal of Design, 3(2), 41-51.

Evans, A. T., \& Clark, J. K. (2012). Source characteristics and persuasion: The role of self-monitoring in self-validation. Journal of Experimental Social Psychology, 48(1), 383-386.

Fishbein, M. (1967). Attitude and the prediction of behavior. In M. Fishbein (Ed.), Attitude theory and measurement (pp. 477-492). New York, NY: John Wiley and Sons, Inc.

Forgas, J. P. (2001). The handbook of affect and social cognition. Mahwah, NJ: Erlbaum.

Horcajo, J., See, Y. H. M., Briñol, P., \& Petty, R. (2008). The role of mortality salience in consumer persuasion. Advances in Consumer Research, 35, 782-783. 
Muehling, D. D., \& Sprott, D. E. (2004). The power of reflection: An empirical examination of nostalgia advertising effects. Journal of Advertising, 33(3), 25-35.

Pascal, V. J., Sprott, D. E., \& Muehling, D. D. (2002). The influence of evoked nostalgia on consumers' responses to advertising: An exploratory study. Journal of Current Issues and Research in Advertising, 24(1), 39-49.

Perreault, W. D., \& Leigh, L. E. (1989). Reliability of nominal data based on qualitative judgments. Journal of Marketing Research, 26(2), 135-148.

Petty, R. E., \& Briñol, P. (2015). Emotion and persuasion: Cognitive and meta-cognitive processes impact attitudes. Cognition \& Emotion, 29(1), 1-26.

Petty, R. E., \& Wegener, D. T. (1999). The elaboration likelihood model: Current status and controversies. In S. Chaiken and Y. Trope (Eds.), Dual-process theories in social psychology (pp. 37-72). New York, NY: Guilford Press.

Petty, R. E., Briñol, P., \& Tormala, Z. L. (2002). Thought confidence as a determinant of persuasion: The self-validation hypothesis. Journal of Personality and Social Psychology, 82(5), 722-741.

Petty, R. E., Briñol, P., Valle, C., Rucker, D. D., \& Becerra, A. (2007). The effects of message recipients' power before and after persuasion: A self-validation analysis. Journal of Personality and Social Psychology, 93(6), 1040-1053.

Petty, R. E., Cacioppo, J. T., \& Schumann, D. (1983). Central and peripheral routes to advertising effectiveness: The moderating role of involvement. Journal of Consumer Research, 10(2), 135-146.

Petty, R. E., Harkins, S. G., \& Williams, K. D. (1980). The effects of group diffusion of cognitive effort on attitudes: An information processing view. Journal of Personality and Social Psychology, 38(1), 81-92.

Petty, R. E., Schumann, D. W., Richman, S. A., \& Strathman, A. J. (1993). Positive mood and persuasion: Different roles for affect under high and low elaboration conditions. Journal of Personality and Social Psychology, 64(1), 5-20.

Schwarz, N., Bless, H., \& Bohner, G. (1991). Mood and persuasion: Affective states influence the processing of persuasive communications. Advances in Experimental Social Psychology, 24, 195-202.

Swinyard, W. R. (1993). The effects of mood, involvement, and quality of store experience on shopping intentions. Journal of Consumer Research, 20(2), 271-280.

Tormala, Z. L., Briñol, P., \& Petty, R. E. (2006). When credibility attacks: The reverse impact of source credibility on persuasion. Journal of Experimental Social Psychology, 42(5), 684-691.

Tormala, Z. L., Briñol, P., \& Petty, R. E. (2007). Multiple roles for source credibility under high elaboration: It’s all in the timing. Social Cognition, 25(4), 536-552.

Tormala, Z. L., Petty, R. E., \& Briñol P. (2002). Ease of retrieval effects in persuasion: A self-validation analysis. Personality and Social Psychology Bulletin, 28(12), 1700-1712.

Wright, P. (1980). Message-evoked thoughts: Persuasion research using thought verbalization. Journal of Consumer Research, $7(2), 151-175$. 